\title{
The effects of chosen governmental financial policy measures aimed at Croatian islands' economic sustainability enhancement with special stress on tourism
}

\author{
M. Krneta ${ }^{1} \&$ S. Pivčević ${ }^{2}$ \\ ${ }^{1}$ Croatian Bank for Restructuring and Development, Split, Croatia \\ ${ }^{2}$ Faculty of Economics, University of Split, Split, Croatia
}

\begin{abstract}
In line with the normative frame, the majority of Croatian islands are accounted as areas with unfavourable business/economic environments. The pronounced depopulation is viewed as a result of the inexistence of an economic base necessary for keeping the population on islands. Sustainable development, however, presumes not only environmental and socio-cultural sustainability but an economic one as well. Economic sustainability, viewed from a business operations perspective, calls for using resources in a way that enables the business to function over a number of years, while consistently returning a profit. On a state, regional and local level, numerous measures of economic development stimulation for island economies have been introduced so far. They are, to a large extent, aimed at financial support of island-based business subjects. Such policy comes from the assumption that the island business environment is more hostile compared to that of the mainland and consequently the access to financial sources unfavourable. The main goal of this article is to analyze the effects of some governmental economic policy measures aimed at island economy stimulation dominantly through the non refundable forms of financial assistance and credit lines with favourable/stimulating conditions. The results are valuable in determining which economic activities have been the objects of entrepreneurial interest on Croatian islands as well as for revealing the effects of these policy measures. As such, it creates a valuable base for possible
\end{abstract}


policy adjustments aimed at enhancement of the overall economic sustainability of Croatian islands.

Keywords: economic sustainability, Croatian islands, government, financial policy measures, tourism.

\section{Introduction}

Although the concept of sustainable development is widespread and used, it still lacks a universally accepted practical definition [1]. Still, over the last decades of, the concept of sustainability has evolved to encompass three major aspects of sustainability: economic, social and environmental [2]. The environmental aspect of sustainability focuses on the overall viability and health of ecological systems by taking care of natural resource degradation, pollution, and loss of biodiversity. This aspect of sustainability attracted most attention of researches so far [3-6]. Social sustainability, on the other hand, focuses on reducing vulnerability and maintaining the health of social and cultural systems by strengthening the social capital through empowerment $[1,7,8]$. Constituting elements of this approach are preserving cultural diversity and cultural capital, strengthening social cohesion, partnership and networks [9]. Last, but not least, the economic sustainability is concerned with the issue of human welfare improvement, primarily through growth in the consumption of goods and services $[1,2]$. A more practical definition says it is the ability to support a defined level of economic production indefinitely [10] while it can also be described as the process of allocating and protecting scarce resources, while ensuring positive social and environmental outcomes [11]. Economic efficiency plays a key role in ensuring both efficient allocation of resources in production, and efficient consumption choices that maximize utility. Problems arise in the valuation of non-market outputs (especially social and ecological services), while issues like uncertainty, irreversibility and catastrophic collapse pose additional difficulties [9].

When island economies and societies are discussed, unique development problems arise, especially if the islands in case are located far from their major markets. Most important issues defining and determining island economies are smallness and remoteness [12]. Due to the discontinuity of the geographical space, the latter seems to be the most distinguishable characteristic of all island societies [13]. Kakazu (as cited in [13]) however suggests that for improved understanding, analysis and classification of island areas the measurement of an island has to take into consideration additional factors, like isolation, migration and external sources of income (especially tourism). These handicaps are evident and pronounced in islands economies globally and call for actions and incentives for improving the positions of these communities/economies. For example, Island Regions of the European Union drafted a Manifesto [14] calling for measures aimed at improving their unfavourable competitive position. The objective they aimed at was set in motion by Article 158 of the Treaty of Amsterdam which gave particular importance to reduction of the backwardness of less favoured regions as a means of achieving the goals of economic and 
social cohesion. The reasoning manifesto was based on suggested that effective consideration of the handicaps faced by EU Island Regions like isolation from larger markets, seasonality, loss of high quality human resources, and other structural problems, must be transformed into specific political actions and clear legal provisions, fully integrated in the system of European decisions.

On the other, there are also those [13] arguing that a number of island area's characteristics can be considered as their advantages over larger areas. The main advantage is the enormous potential of island economies to develop tourism.

\section{Impact analysis of sustainable development of islands in Croatia}

The Republic of Croatia has 1244 islands which are geographically defined as 78 islands, 525 small islands and 641 cliffs and reefs. The islands encompass $3259 \mathrm{~km}^{2}$ constituting $5,8 \%$ of country's area. Of that 50 islands are permanently inhabited [15]. According to the latest Census [16], an increase in the island population is in place and nowadays they count 132,443 inhabitants, i.e. 7500 more than in 2001. Croatian authorities invest cca 16 million Euros on yearly basis in development of necessary infrastructure, subventions and diverse support [15].

In Croatia there are specific laws and regulations concerning areas with unfavourable development conditions termed Areas of special state care. These include foremost islands and rural areas. Furthermore, special incentive programs for targeted business groups and economic sectors, including various forms of financing, are developed and implemented. Therefore it can be concluded that there is a regulatory framework for enhancement of country's economic development, including small businesses. Generally, the support programmes consist of grants and loans with favourable financing terms and reduced interest rate. In the recent 19 years, the Croatian Bank for Reconstruction and Development, functioning as a state development bank, has funded a total of more than 29 thousands projects, worth around 63 billion HRK, $13 \%$ of which relates to loans for small business [17]. It is estimated that the sector of small businesses, as defined by special law, has about 178 thousand active businesses [18]. Only in the period, 2008-2010 a total of approximately 0.77-million HRK grants in more than 15.7-thousand individual grants [18], excluding grants for different purposes approved by the agriculture sector, were used. Since these measures are programmed and implemented with the aim of improving the position and development of firms in the SME category, it is of great importance to analyze their effects. That means analyzing primarily (1) if the purposes of using funds are consistent with the policy measures and incentives, and (2) the effects of the funds usage in terms of achieving the goals set by policy incentives. Within the context of sustainable development of Croatian islands and economic development stimulation policy, the objects of this research are: (1) the degree of utilization of SME support programmes' resources by business entities on Croatian islands, particularly in relation to 
funds usage and (2) the effects of using support on business performance of entities on islands.

\subsection{Conceptual research model of impact analysis}

Given the subject of the research, the conceptual research model has been constructed (Figure 1). In terms of content of analysis, the model includes: (1) forms of support i.e. grants and loans, and (2) the usage of support (competitiveness, innovation, co-operative enterprise, targeted activities, etc.). The scope of the analysis relates to: (1) the share/frequency of businesses with both operations and headquarters being on islands in the Republic of Croatia, in the use of support (grants and loans) in total funds available in the analysed period, and (2) the estimate of effects of used funds through analysis of selected business indicators. The first level of analysis is an indication of entrepreneurship of island's businesses population as well as indicator of island economies' sustainable development. The second level of analysis reveals entrepreneurial intent of island small business owners and managers and serves as an indicator of their long-term development. That, however, is considered a key building stone for preventing depopulation of the islands' working population.

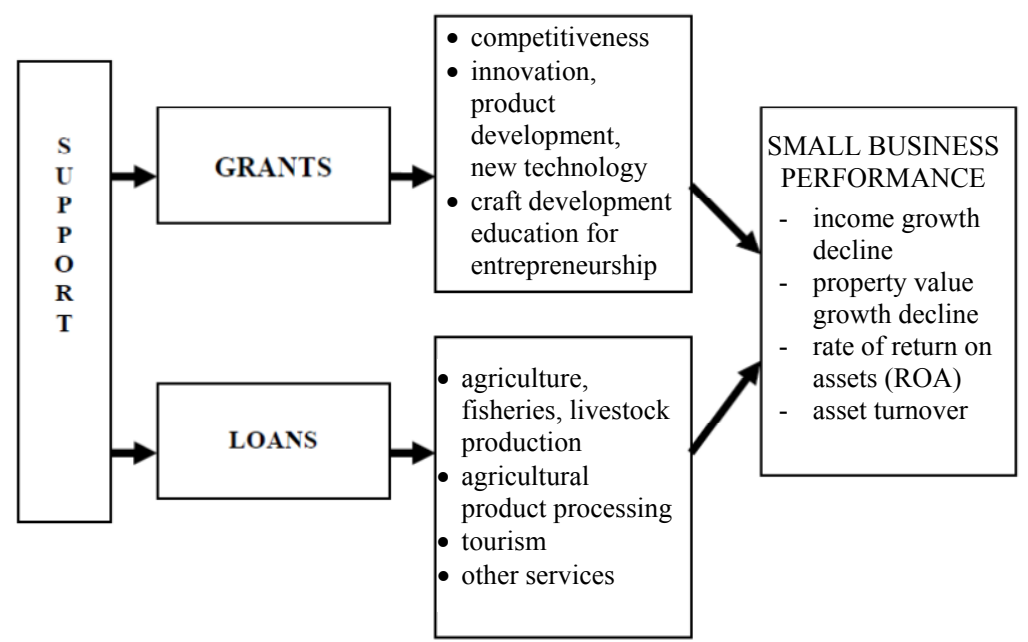

Figure 1: The conceptual model of analysis of support effects on sustainable development of Croatian islands.

In the support programmes scheme, grants are determined by a separate program and are dedicated for increasing the competitiveness of businesses, investment in innovation, new products and technology, entrepreneurship education and training, and crafts development. Credit funds, on the other hand, are determined by special loan programs and are dedicated for investments in agricultural production, fisheries and breeding animal cultivation, organic 
production, semi-intensive and extensive sheep and goat breeding, fish and shellfish farming, processing industry, especially with the Croatian island product label, stone carving, masonry, ecotourism and sustainable tourism development, and traditional processing regarding production of souvenirs and small shipbuilding.

\subsection{Methodology}

In line with the research goal, the research has focused on: (1) grants used to strengthen the SME's sector competitiveness, (2) credit funds dedicated for financing SME businesses that operate in island communities, and (3) the impact of used grants and dedicated funds on performance of businesses on the islands.

Given the established framework of research, the first step is the analysis of available data about used grants and dedicated funds in the period between 2008 and 2010 by businesses. The second step is the analysis of businesses that took advantage of the largest part of the dedicated resources, by using the selected set of indicators of business performance. As a result of restricted data availability, both analyses are based on the sample of businesses with their headquarters on islands in four Dalmatian counties (Zadarska, Šibensko-kninska, Splitskodalmatinska, Dubrovačko-neretvanska) with population of about 43 thousands businesses (or $22 \%$ of the total population of active businesses in Croatia at the end of 2010 year) [19]. The sample consisted of 37 companies with three-year data set of operations (2008-2010). The data on support measures (grants and loans) were obtained from the Croatian Bank for Reconstruction and Development while the business performance indicators were calculated based on the data authors extracted from profit and loss statement and balance sheet of business entities in sample [20]. A set of following performance indicators have been analysed: (1) the rate of growth/decline of income, (2) the rate of growth/decline in value, (3) rate of return on assets, (4) ratio of business activities. If the analysis was to be comprehensive it ought to include also the data on business dynamics i.e. the rate of business birth, closure and survival on islands. However, as such data are not available; the authors had to settle with business performance indicators only.

\subsection{Results}

According to the strategy of encouraging small and medium enterprises in the country, grants are aimed at strengthening the competitiveness, ensuring balanced regional development and strengthening the investment climate. The total value of grants used in the period from 2008 to 2010 on various grounds is around 105 million $€$. Out of that, small and medium entrepreneurs in the Adriatic region (one of the three statistical NUTS 1 regions in Croatia, encompassing seven counties on the Adriatic) used $24 \%$ of total funds [21]. The economic potential of this region in terms of the number of active businesses in the same period was approximately 83,000 businesses, or $41 \%$ of the total number of active businesses in the country [21], mostly in the group of small and medium businesses. 
Table 1: Utilization of grant funds by small and medium sized business entities in Croatia, Adriatic region and on islands (2008-2010).

\begin{tabular}{|l|r|r|r|}
\hline \multicolumn{1}{|c|}{ Item } & \multicolumn{1}{|c|}{ Value } & Percentage & \multicolumn{1}{|c|}{$\begin{array}{c}\text { Average } \\
\text { (HRK) }\end{array}$} \\
\hline 1. Utilized grants - (2008-2010) - in millions & & & \\
\hline 1.1. Croatia & 768.61 & $100.0 \%$ & 4220 \\
\hline 1.1. Adriatic region & 184.47 & $24.0 \%$ & 2.22 \\
\hline 1.3. Islands [22] & 0.38 & $0.1 \%$ & 50 \\
\hline $\begin{array}{l}\text { 2. Number of small businesses - } \\
\text { (average 2008-2010) - in thousands. }\end{array}$ & & & \\
\hline 2.1. Croatia & 182.00 & $100.0 \%$ & \\
\hline 2.2. Adriatic region & 83.12 & $45.7 \%$ & \\
\hline 2.3. Islands & 8.31 & $4.6 \%$ & \\
\hline
\end{tabular}

In the period from 2008 to 2010 , each small and medium enterprise in Croatia used on average a $4200 \mathrm{HRK}$ (cca $557.10 €$ ) grant to strengthen competitiveness. In the Adriatic region that amount is $2200 \mathrm{HRK}$ (cca 291.81€) while on the islands only 50 HRK grant (cca $6.60 €$ ). This simple analysis of territorial distribution of grants utilization of SMEs shows that areas with less favoured economy conditions, including the islands, have hindered access to the resources aimed specifically at strengthening their competitive position. For example, out of the total value of grants in 2010 year (253.56 million HRK), small and medium-sized enterprises in economically most developed part of Croatia (Northwestern region) took advantage of $29 \%$ and $21 \%$ in the capital city Zagreb [23].

In addition to general business conditions in those areas, the ability of SMEs to compete and successfully use dedicated funds can also be subject to special investigation. Capacity development of SMEs on the islands to successfully identify appropriate resources of competitiveness encouragement, and to compete for their use is particularly important in the context of Croatian accession to the EU and the availability of funds under the Structural and Cohesion Funds as well. In a broader sense, strengthening the competencies does not include only strengthening the financial capacity of businesses in the SME category but also the improvement of knowledge and skills of their owners and employees.

As far as the loan funds with favourable conditions are concerned, in the analysed period loan funds worth 570 million HRK in 113 loans were used, or an average around 5 million per business entity. Most of these funds (74\%) were used to finance current operations [24] whilst a quarter was related to long-term investments. Specifically, in the circumstances of financial crisis, businesses on the islands used dedicated funds to finance their survival rather than funding long-term investments in growth and development. Frequency of use of dedicated funds by activities shows that the highest relative share of capital was used in production (36\%) and processing (46\%), including fish processing 


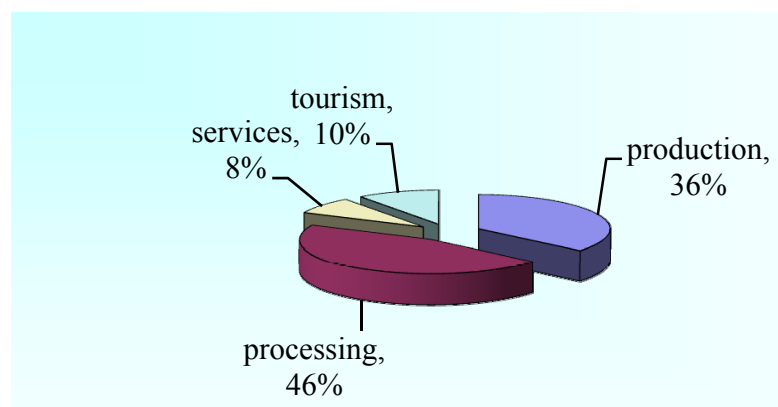

Figure 2: The distribution of loan funds by sectors of island business entities.

(Figure 2). Entities involved in tourism have used only $10 \%$ of dedicated funds and in other services $8 \%$.

As for the same analysis in four Dalmatian counties, island business entities in these regions used $23 \%$ of dedicated funds through 37 loans. Out of that, $84 \%$ funds were used for financing current business operations and only a minor part for long-term investments. Loan activity increased among businesses in the fishing industry (42\%) and manufacturing (39\%). The service sector used $11 \%$ while tourism only $6 \%$ i.e. substantially less as on the islands as whole. Among the most loan active businesses in the manufacturing and processing industries are farming, fishing and fish processing - nearly 4/5 of used dedicated funds are related to firms in these sectors. Obviously, in these sectors (fishing and farming of oily fish), there is a number of SME entrepreneurs that use convenient market opportunities meaning that they have the necessary knowledge and skills for the successful use of favourable sources of financing. On the other hand, an insight into structure of fund users by size shows that these are mostly in the medium sized category while micro-businesses are rare. This shows that although they are more numerous in observed island economies they do not make use of support measures respectively i.e. sources of funding remain largely inaccessible for them. s In relation to the structuring of business entities by economic activities that are relatively more frequent users of the dedicated funds, it is not irrelevant that these are businesses of intensive economic activity (fishing, farming) which can have long term negative consequences to both sustainable economic development of island communities, and the environment e.g. in harvesting of certain types of fishing, pollution of the seabed and the sea, and the like. Foremost, these are economic activities that do not go hand in hand with tourism so their development must be carefully planned and monitored.

As mentioned before, an important element is the analysis of the effects the support measures have had on the business performance of business entities that have used them. In this part, it is important to note that a quarter of firms in the sample have been operating only for one year so the analysis is restricted. The analysis performed shows that targeted grants and dedicated funds have helped island entrepreneurs face the consequences of economic and financial crisis. 
They have to a most part (56\%) recorded the fall of total revenues in the observed three-year period, while a quarter of them has recorded an income increase. This finding has to be viewed in the light of the global crisis and in such circumstances it is quit expected. On the other hand, substantial share of entities in the sample (44\%) has recorded an increase in the property value (Figure 3).

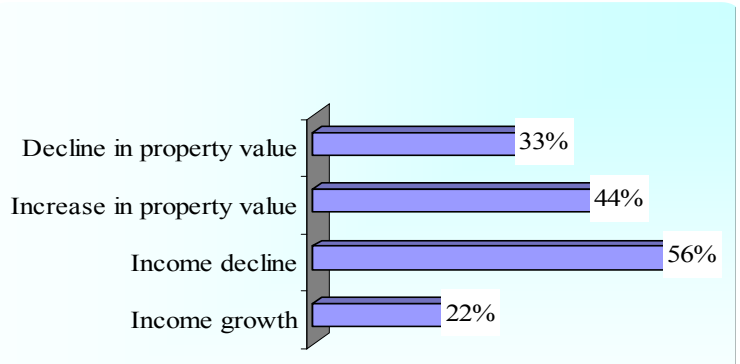

Figure 3: Distribution of island business entities who used state support according to the income and property value change (2008-2010).

As far as the ROA is concerned, the analysis shows that most business entities in the sample $(41 \%)$ have zero rate of return on business assets, one third has achieved a rate of return of $5 \%$ and less while $15 \%$ have a ROA from $6-10 \%$. (Figure 4).

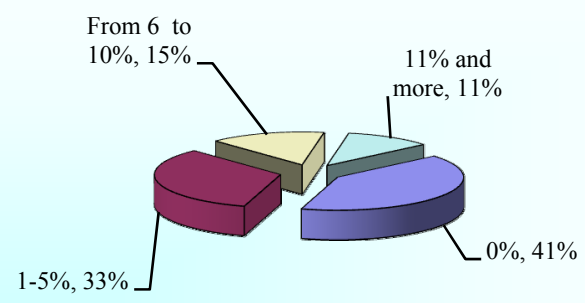

Figure 4: Distribution of island business entities which used state support according to the rate of return on assets (ROA) (2008-2010).

Analysed businesses have also recorded a modest business activity. Only 4\% have achieved an average turnover of business assets greater than 2. Most of them $(2 / 3)$ have achieved asset turnover ratio of less than 1 while one third has asset turnover ratio between 1and 2 (Figure 5). 


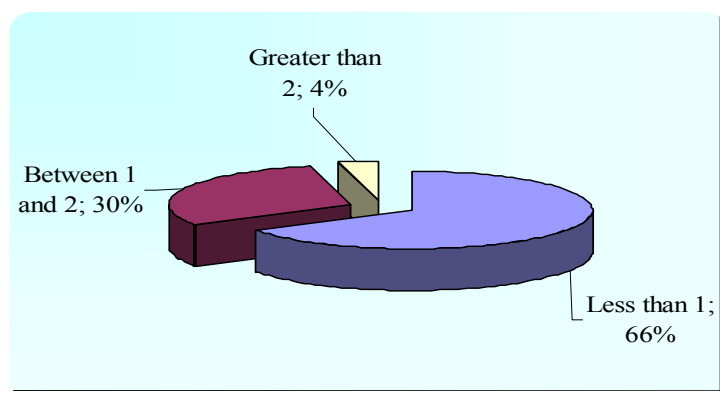

Figure 5: Distribution of island business entities who used state support according to asset turnover ratio (2008-2010).

Thus, the analysis of businesses performance indicators of island business entities that have used support schemes reveal a mixed picture - most entities have reported income decline, a zero ROA and modest asset turnover ratio while, as a positive finding, the majority has reported an increase in property value. However, to be able to position these finding correctly it would be necessary to compare these indicators to the periods before entities used the support scheme or to compare them to business of other island entities that have not used support schemes. However, both of these data sets are unavailable so such comparisons remain elusive.

\section{Conclusion}

Economic activity on the islands is an important prerequisite for reducing outflow of island population. In Croatia, there is an appropriate regulatory framework, set of strategies and policies and measures to encourage economic activity on the islands. As it is all about operations in harsh economic conditions, the availability and use of grants and dedicated funds on terms more favourable than the commercial ones can have a positive impact on improving the business dynamics of businesses on the islands, given the formation of new businesses and increase of the survival rate of the existing ones.

Results of analysis availability, utilisation and effect of funds dedicated for the islands' entrepreneurs indicate their limited ability to compete for, secure and use grants and favourable loan funds. Namely, SMEs from islands have used only $0.1 \%$ of all used funds in the observed period. This figure speaks for it self and demonstrates that analyzed support measures for some reason do not reach island SMEs. Also, the analysis has revealed that relatively more funding of this type is used by business entities in the group of small and medium businesses. In other words, micro entrepreneurs are the ones that use these funds to the smallest extent and that can have a long-term negative impact on sustainable development of islands' economy and environment. Although tourism is one of the major sources of income on Croatian islands and one of the main proclaimed pillars of their future development, the analysis has showed that tourism SME are not using much of the support measures under investigation $-10 \%$ of all used funds 
on islands in general and only $6 \%$ in the four Dalmatian counties . If tourism is to be the pillar for island development, actions are needed to change these figures. On the other hand, most active in the support funds usage are production and processing, including fish processing. As far as the usage of funds is concerned, faced with consequences of economic and financial crisis, island businesses mainly used dedicated funds to maintain the existing scope of business, or even survival, rather than growth and development. This finding doesn't leave a positive outlook for the future but is perfectly expected in the given circumstances. On the other hand, the question is how stronger would the negative consequences of the crisis be if it weren't for these funds? We believe much stronger.

There are important limitations encountered throughout the research process that need to be stressed here. They foremost relate to the (un)availability of data on (1) the dynamics of businesses on the islands and exploited grants in the period before 2008, and (2) businesses performance of island business entities for a longer periods. As a result of the first limitation, the used sets of indicators of business performance are static ones while the result of the latter is the restriction of analysis to the period/years of global economic and financial crisis. For sure, the analysis of business in more "normal" global conditions would give different picture. These limitations are also guidelines for future research projects in this area.

Although these limitations impose limitations to the conclusions arrived at, they seem to be important regarding at least two circumstances. First is the fact that there are very few research studies and analyses dealing with the effects of specific policies and measures for encouraging economic activity, particularly for the SME population operating in harsh economic conditions. That makes it difficult, if not impossible, to discus with arguments the long-term success of such policies and measures. Secondly, the existence of comprehensive and current data on business entities on islands is the key prerequisite in defining, implementing and monitoring the effects of strategies, policies and measures of stimulation and support for the sustainable economic development of islands. For that reason, we conclude our paper by articulating an urge for such a data base creation.

\section{References}

[1] Petrić, L., Croatian Tourism Development Model - Anatomy of an Un/Sustainability (Chapter 6), Sustainable development - tourism, life science, management and environment, ed. G. Ghenai, Intech, pp. 119-146, 2012.

[2] Kates, R. W., Parris, T. M. Leiserowitz, A., A., What is sustainable development - goals, indicators, values, and practice, Environment: Science and Policy for Sustainable Development, 47 (3), pp. 8-21, 2005.

[3] Hall, C. M., Lew A. A., The Geography of Sustainable Development; an Introduction (Chapter 1), Sustainable Tourism: A Geographical 
Perspective. eds. C. M.Hall and A. Lew, Pearson Education Limited: Harlow, pp. 1-12, 1998.

[4] Hall, D., Sustainable Tourism Development and Transformation in Central and Eastern Europe. Journal of Sustainable Tourism, 8 (6), pp. 441-457, 2000.

[5] United Nations Development Programme (UNEP), Priority products and materials: assessing the environmental impacts of consumption and production, 2010 .

[6] Weaver, D. Sustainable Tourism, Elsevier Butterworth- Heinemann: Oxford, 2006.

[7] Simmons, D., Community participation in tourism planning. Tourism Management, 15 (2), pp. 98-108, 1994.

[8] Petrić, L., Empowerment of Communities for Sustainable Tourism Development, Case of Croatia, Turizam, 55 (4), pp. 431-443, 2007.

[9] Munasinghe, M. Analysing the Nexus of Sustainable Development and Climate Change: an Overview, Organisation for Economic Cooperation and Development (OECD), 2003; retrieved from http://www.oecd.org/ dataoecd/32/54/2510070.pdf

[10] http://www.thwink.org/sustain/glossary/Sustainability.htm

[11] Doane, D., MacGillivray, A., Economic Sustainability - The business of staying in business, New Economics Foundation, 2001.

[12] Kakazu, H., Sustainable Development of Small Island Economies, Boulder: Westview Press, 1994.

[13] Rontos, K., Kitrinou, E., Lagos, D., Diakomihalis, M., Islands and Tourism Development: A Viewpoint of Tourism Stakeholders of Lesvos Island (Chapter 22), Visions for Global Tourism Industry - Creating and Sustaining Competitive Strategies, ed. M. Kasimoglu, INTECH, pp. 461478, 2012.

[14] Manifesto of the Island Regions of the European Union (2005), http://www.insuleur.net/doc/manifesto-ENG.pdf

[15] Ministry of regional development and EU funds, http://www.mrrfeu.hr/ default.aspx?id $=642$ )

[16] Croatian Bureau of Statistics, Census 2011, http://www.dzs.hr/Hrv/ censuses/census2011/censuslogo.htm

[17] Croatian Bank for Reconstruction and Development (HBOR), Annual report for 2010; www.hbor.hr

[18] Croatian Government, Operational plan for the promotion of small and medium enterprises for 2011 year; www.minpo.hr

[19] Croatian Chamber of Trade and Crafts, www.hok.hr

[20] www.bonitet.hr

[21] Croatian Chamber of Trade and Crafts, http://www.hok.hr/ cro/statistika/trgovacka drustva i obrti

[22] Authors' assessment based on published data on individual aid granted to businesses, according to purpose, for the period 2008-2010. Ministry of economy, labour and entrepreneurship; www.mingorp.hr 
62 Island Sustainability II

[23] Ministry of economy, work and entrepreneurship, SME Operating Plan for 2011 year; www.mingorp.hr

[24] Croatian Bank for Reconstruction and Development data on the number and value of loans for island's SMEs; www.hbor.hr 